\title{
Using GIS for Measuring Transit Stop Accessibility Considering Actual Pedestrian Road Network
}

\author{
Mohamed A. Foda, Arab Academy for Science \& Technology \\ Ahmed O. Osman, University of Toronto
}

\begin{abstract}
Bus stops attain their importance to the transit service from being the main points of contact between the passenger and the bus. Considering spatial attributes, both the location and the spacing of bus stops significantly affect transit service performance and passenger satisfaction, as they influence travel time in addition to their role in ensuring reasonable accessibility. Knowing that every transit trip begins and ends with pedestrian travel, access to a bus stop is considered a critical factor for assessing the accessibility of the stop location. In this research, transit stop access coverage is estimated based on the actual pedestrian road network surrounding the stop. Accordingly, new indices are developed to assess a bus stop location on a more spatial basis. These indices measure the accessibility of a bus stop through the surrounding road network in addition to the ratio of actual access coverage to the ideal access coverage of a stop.
\end{abstract}

\section{Introduction}

Being the first points of contact between the passenger and the transit service, access to public transport stops is an important factor affecting overall transit trip travel time. Physical access to a transit stop is interpreted in terms of the proximity of the passenger's origin or destination to the nearest transit stop (TCRP 1996), 
which is generally achieved by walking, riding a bicycle or driving a car for a short distance (Murray and Wu 2003). In planning for the provision of bus-based transit service, accessing a bus stop is considered to be achieved mainly by walking. Based on an assumed average walking speed of about $1.3 \mathrm{~m} / \mathrm{s}, 5$ minutes of walking is considered reasonable in urban areas, which is about 400 meters in terms of walking distance (Levinson 1992). Most transit firms consider 400meters an acceptable access/egress standard (Ammons 2001). In Columbus, Ohio, it is stipulated that passengers do not exceed walking distances of $400 \mathrm{~m}$ to transit stops in urban areas (Central Ohio Transit Authority 1999). In general, access to transit stops affects passenger accessibility and represents the opportunity to use the public transport service (Holtzclaw 1994).

\section{Estimating Bus Stop Access Coverage}

Although pedestrian access to a bus stop is achieved through the pedestrian road network surrounding each stop, previous research has not focused on the interaction between bus stop locations and their surrounding pedestrian road networks. Stop access coverage has been estimated using a circular buffer analysis with a radius of the access threshold around the transit stop in order to identify its coverage area. Knowing this area in addition to the population density, the total number of individuals in a region having suitable access can be determined. Another approach for estimating access is by comparing the distance from the centroid of a spatial block to its nearest bus stop. If this distance is within the threshold distance, then coverage is achieved (Murray et al. 1998). Both approaches provide simple estimates for access coverage; however, they are unrealistic and have potential for error by measuring the access distance in terms of a rectilinear distance and ignoring the actual geography of the pedestrian road network surrounding the stops.

\section{Estimating Actual Bus Stop Access Coverage}

Bus stop access coverage is a critical measure for evaluating the stop location by estimating the covered area and population lying within a suitable access distance from the bus stop (Foda and Osman 2008). However, much previous research treated stop coverage as a simple circular buffer with a radius of the access threshold around each stop, which causes an overestimation of the stop access coverage. The reason for such an overestimation is the implied assumption that passengers can reach the bus stop from any location within the circular buffer (ideal case), 
and neglecting the actual geography of the pedestrian road network surrounding the bus stop, as shown in Figure 1.

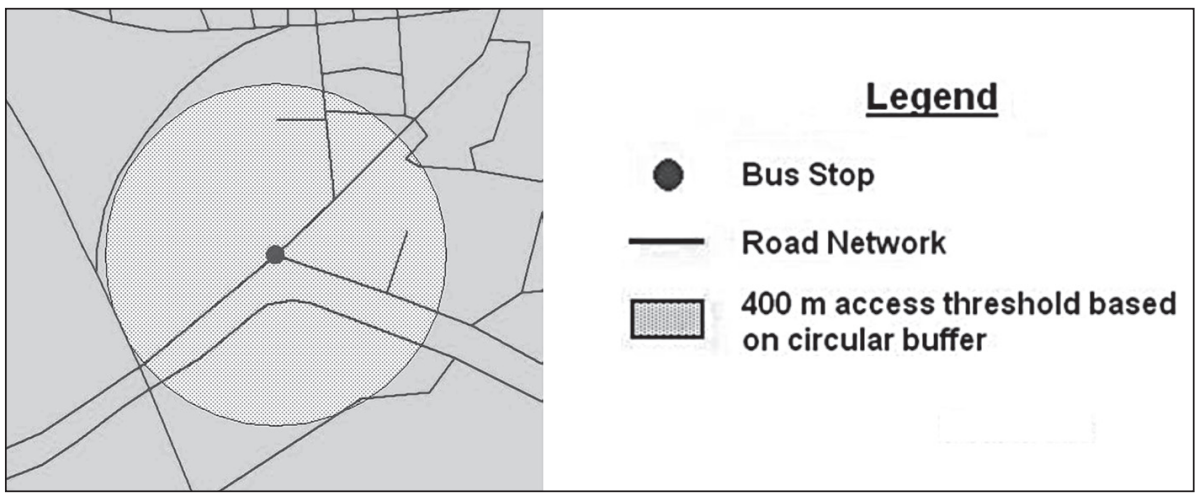

\section{Figure 1. Bus Stop Access Coverage Based on a Circular Buffer Around the Stop and Neglecting the Actual Pedestrian Road Network}

The accessibility to a bus stop from within the circular buffer zone and through the intersected road network located inside the buffer area can be divided into two parts: the first is within the specified limit of $400 \mathrm{~m}$, and the other exceeds the limit, as shown in Figure 1. That is, although the start of the walking distance is located within the circular buffer, it exceeds the specified distance of $400 \mathrm{~m}$.

While being an important measure for the assessment of a stop location, estimating the actual access coverage is complicated by the practical realities of spatial information. This means that proximity to stops must be interpreted creatively, which is possible using the powerful GIS network analysis functions (Foda and Osman 2006). Fortunately, most commercial GIS packages offer capabilities for carrying out assessment of access on the basis of the actual pedestrian road network. Salvo and Sabatini (2005) suggested a more spatial approach for identifying optimal stop locations. They proposed a methodology to assess public transportation access coverage in urban areas using a geographical information system based on a pedestrian network with the presence of obstacles.

In this research, and using the benefits of the GIS network analysis functions, another approach is presented for estimating transit stop access coverage based on the actual pedestrian road network surrounding the bus stop. The idea here is to identify all the pedestrian road network links that lie within the specified maximum walking distance of the $400 \mathrm{~m}$ access threshold, measured along the network paths around the bus stop. Joining the ends of those links creates a polygonal area, 
which is referred to as the "actual access coverage" for the bus stop. This polygonal area is considered more representative than a $400 \mathrm{~m}$ circular buffer for measuring the access coverage of a bus stop. Figure 2 shows the difference between the ideal access coverage (circular area) and the actual access coverage (polygonal area), which causes an overestimation in assessing the access coverage of a bus stop at a given location.

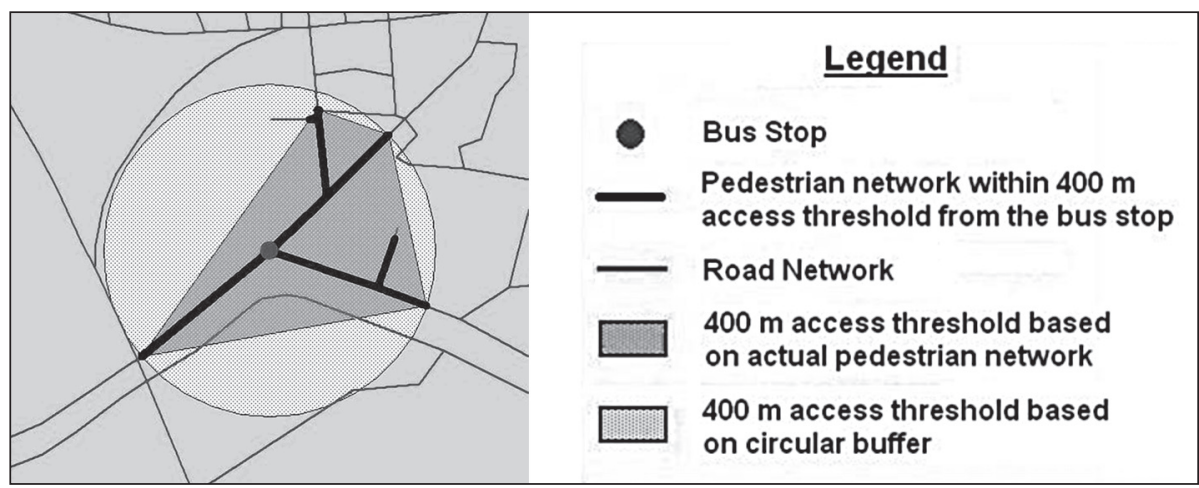

\section{Figure 2. Ideal (Circular) and Actual (Polygonal) Bus Stop Access Coverage}

By applying the presented approach for estimating bus stop access coverage, new assessment indices are developed in an attempt to provide a more spatial evaluation of the bus stop location. These indices can be used to evaluate both the accessibility to a bus stop through the surrounding pedestrian road network and the ratio of actual access coverage to the ideal access coverage of a bus stop.

\section{Ideal and Actual Stop-Accessibility Indices (ISAI and ASAI)}

First, the Ideal Stop-Accessibility Index (ISAI) can be used to evaluate the accessibility to a bus stop through the surrounding pedestrian road network. This is obtained by dividing the total length of the pedestrian road network links lying within a walking distance of $400 \mathrm{~m}$ measured along the network paths $(\mathrm{Km})$ by the ideal access coverage area of the bus stop measured as a circle with a radius of $400 \mathrm{~m}$ and having the bus stop as its center $\left(\mathrm{km}^{2}\right)$, as shown in Figure 3. 


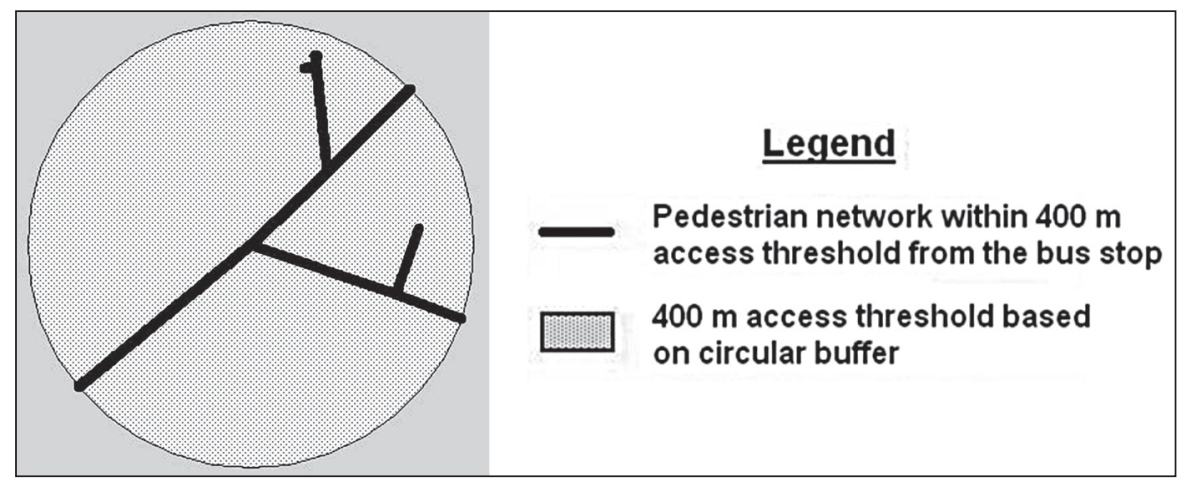

Figure 3. Ideal Stop-Accessibility Index (ISAI)

The denominator value is then the area of a circle with a radius of $400 \mathrm{~m}$, which is a constant equal to $\left(\pi r^{2}=\pi \times(0.4)^{2}=0.503 \mathrm{Km}^{2}\right)$, in which the resulting value of such an index represents the ideal pedestrian road network density within the access threshold from a bus stop $\left(\mathrm{Km} / \mathrm{Km}^{2}\right)$. The flowchart presented in Figure 4 illustrates the sequence of the different actions needed to compute the ISAI within the GIS platform.

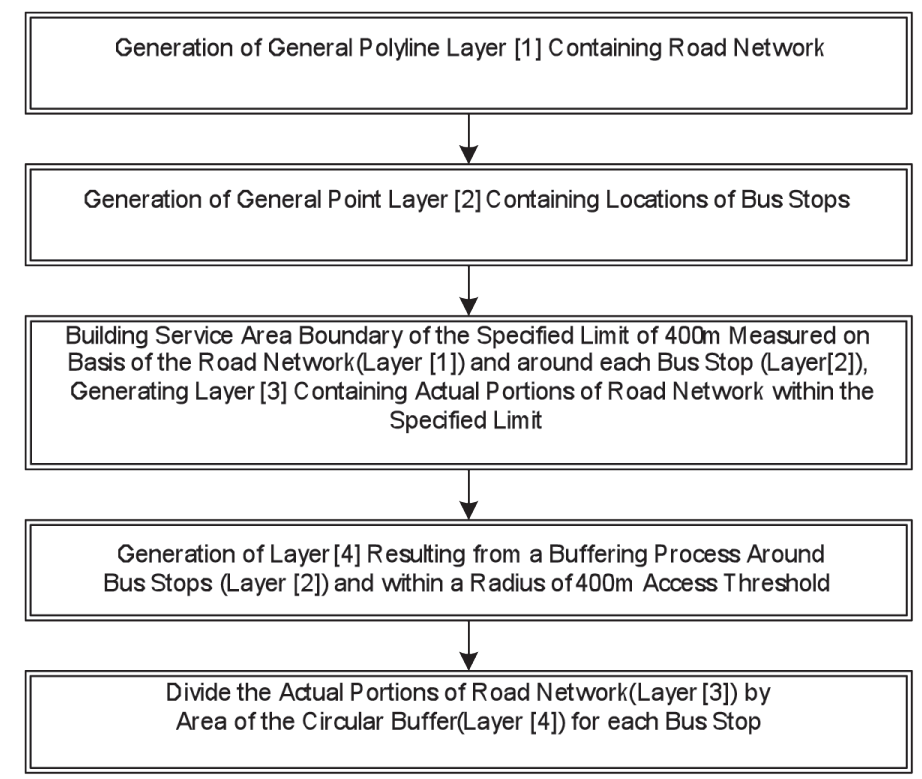

Figure 4. Sequence of Actions to Compute ISAI within GIS Platform 
As previously stated, the ISAI value represents the accessibility to a bus stop through the surrounding pedestrian road network. An increment in the index value means that the ideal pedestrian road network density is higher, which is interpreted in terms of a better connectivity between the bus stop and the surrounding pedestrian road network; hence, the bus stop is more likely to be accessible, and vice versa. In other words, the higher the value of the ISAI, the more accessible the bus stop location.

Second, the Actual Stop-Accessibility Index (ASAI) can be used as a more accurate measure of bus stop accessibility through the surrounding pedestrian road network. It is believed that the ASAI provides a more accurate measurement than the ISAI to the pedestrian road network density around a bus stop, where the denominator represents the actual access coverage area for the bus stop within the $400 \mathrm{~m}$ limit of walking.

The ASAl is obtained by dividing the total length of the pedestrian road network links lying within a walking distance of $400 \mathrm{~m}$ measured along the network paths $(\mathrm{Km})$ by the actual access coverage area of the bus stop measured on basis of the pedestrian road network serving the same stop $\left(\mathrm{km}^{2}\right)$, as shown in Figure 5.

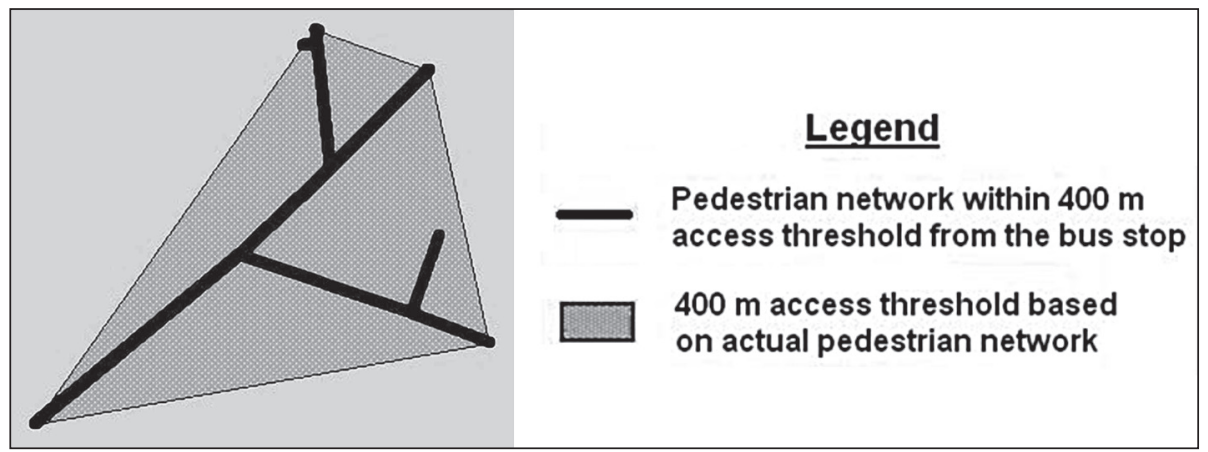

Figure 5. Actual Stop-Accessibility Index (ASAI)

The resulting value of such index represents the actual pedestrian road network density within the access threshold from a bus stop $\left(\mathrm{Km} / \mathrm{Km}^{2}\right)$. The flowchart presented in Figure 6 illustrates the sequence of the different actions needed to compute the ASAI within the GIS platform. 


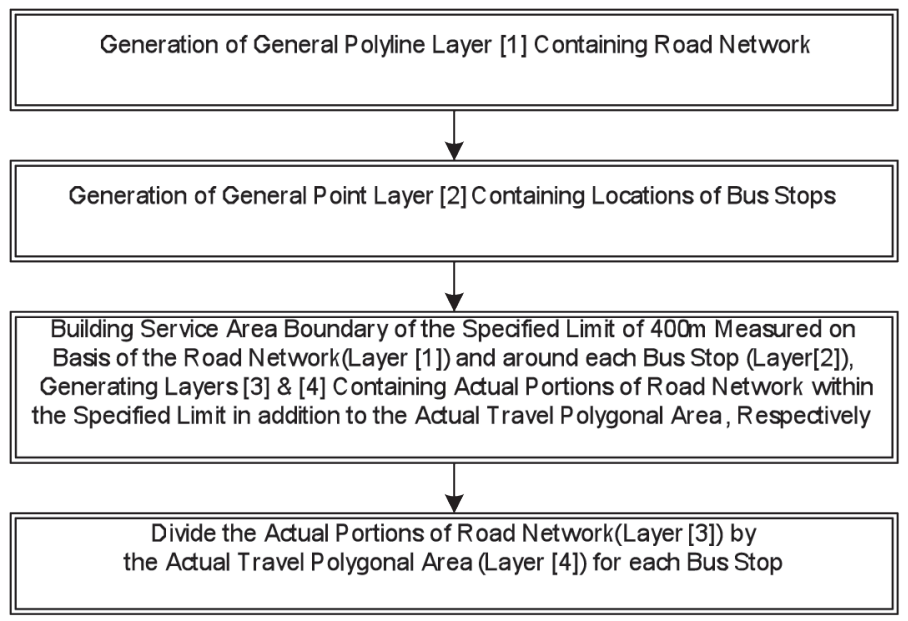

\section{Figure 6. Sequence of Actions to Compute ASAI within GIS Platform}

While the ASAI value estimates the actual pedestrian road network density within the access threshold from a bus stop, it may be misleading if used to compare the accessibility of different bus stop locations, as the denominator is not constant and depends on the surrounding road network formation. The denominator, then, will differ whenever changing the bus stop location, and there will not be a fixed reference to refer to in the comparison. So, when the index value increases, it still will not be clear whether the bus stop is more accessible or not, as this may be a cause of a smaller bus stop access coverage area and not an effect of increasing the pedestrian road network length within the suitable access threshold. Moreover, it should be realized that the actual access coverage area and its shape are affected by the geometry of the pedestrian road network around the bus stop within the suitable walking limit. Further, the ISAI value should always not be greater than the $\mathrm{ASAl}$, as the actual access coverage area will not exceed the ideal.

\section{Stop Coverage Ratio Index (SCRI)}

The Stop Coverage Ratio Index (SCRI) can be used to evaluate the ratio of actual access coverage to that of the ideal access coverage of a bus stop, which is obtained by dividing the actual access coverage area of the bus stop measured on basis of the pedestrian road network paths $\left(\mathrm{km}^{2}\right)$ by the ideal access coverage area measured as a circle with a radius of $400 \mathrm{~m}$ and having the bus stop as its center $\left(\mathrm{km}^{2}\right)$. 
The denominator value is then the area of a circle with a radius of $400 \mathrm{~m}$, which is a constant equal to $\left(\pi r^{2}=\pi \times(0.4)^{2}=0.503 \mathrm{Km}^{2}\right)$, as shown in Figure 7 .

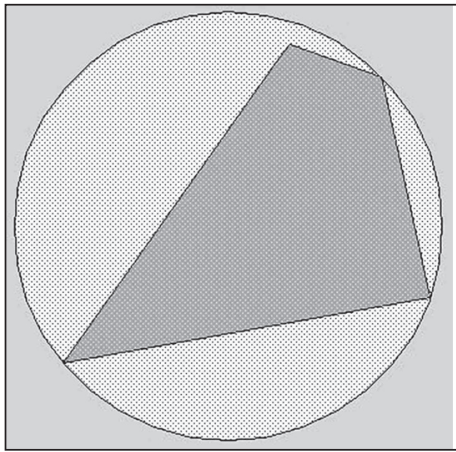

\section{Legend}

$400 \mathrm{~m}$ access threshold based on actual pedestrian network

$400 \mathrm{~m}$ access threshold based on circular buffer

\section{Figure 7. Stop Coverage Ratio Index (SCRI)}

The flowchart presented in Figure 8 illustrates the sequence of the different actions needed to compute the SCRI.

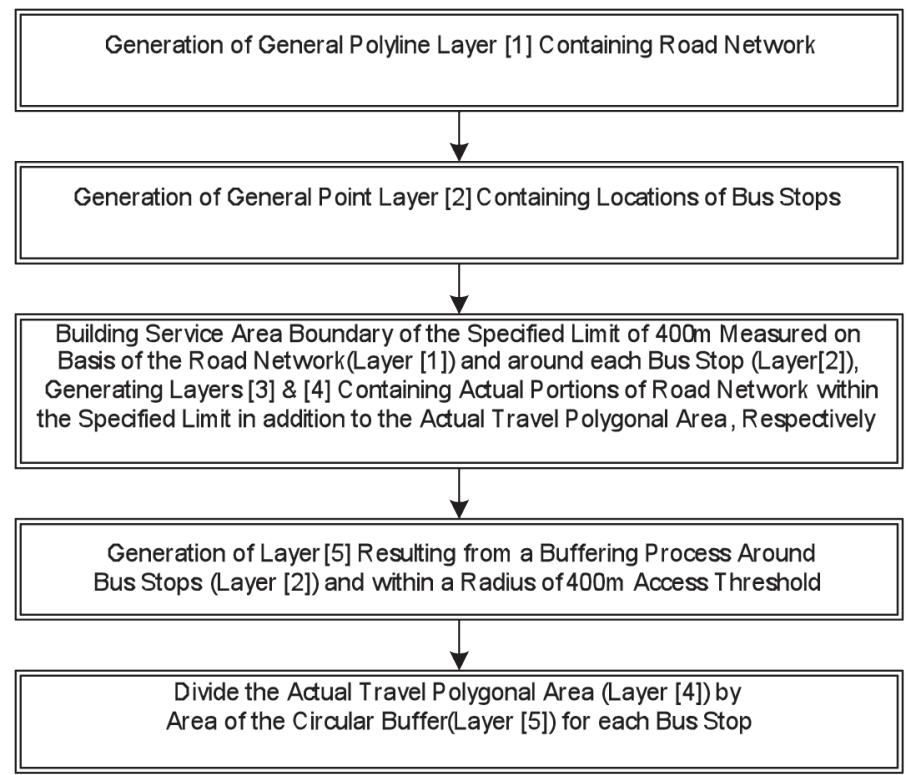

Figure 8. Sequence of Actions to Compute SCRI 
The resulting value of the SCRI is dimensionless, in which it represents the ratio of the actual access coverage to the ideal access coverage of a bus stop. An alternative way for evaluating the SCRI is by dividing the ISAI by the ASAI. Such an index is an indicator of the degree in which the location of the bus stop actually covers the surrounding are-in other words, the percentage of actual access coverage with respect to the ideal access coverage. Further, the population coverage of the stop can be calculated by knowing the population density within the stop's actual coverage area. Theoretically, the index value varies from a minimum of 0.0 if the bus stop is not served with a pedestrian road network to a maximum value of 1.0, which is the ideal case, i.e., actual access coverage area is equal to the ideal access coverage area.

\section{Measuring Ideal and Actual Bus Stops Access Coverage}

Bus stops locations generally are determined by the passenger transporting authority based on goals addressing both traffic operation and passenger accessibility issues. Specifically, how do the stop locations and spacing serve the demand? Further, bus stop spacing affects the overall travel time and, therefore, demand for transit. Stops should be spaced to minimize pedestrian walking distances near major demand generators and to reduce the number of bus stoppages in order not to increase the transit trip travel time; that is, choosing a bus stop location is a tradeoff between stop spacing and travel time. Ensuring suitable stop coverage is a worthwhile objective, as the time taken to reach a public transit stop has a major impact on total trip travel time, which influences potential patronage.

As one of the major roadways in the city of Alexandria, Egypt, the locations of bus stops along Gamal Abd-Elnaser roadway were identified as a case study for the proposed analysis in this research. Gamal Abd-Elnaser roadway, with a length of about $13.13 \mathrm{Km}$ starting from the Bab Sharki district at the west to El-Montaza district at the east, represents one of Alexandria's major longitudinal roadways. The roadway is densely covered with transit bus routes operated by Alexandria Passenger Transporting Authority (APTA). Using a simple GIS buffer analysis, it was found that an area of $10.98 \mathrm{Km}^{2}$ lies within $400 \mathrm{~m}$ access threshold from the bus routes. Further, 31 bus stops were identified serving the bus routes from west to east, as shown in Table 1. 
Table 1. Bus Stops along Gamal Abd-Elnaser Roadway

\begin{tabular}{lc|lc}
\hline Stop No. & Stop Name & Stop No. & Stop Name \\
\hline 1 & Sharki & 17 & Ghanaklis \\
2 & El-Nagda & 18 & Sharawy \\
3 & El-Manara & 19 & Victorya \\
4 & El-Hadara & 20 & Gamal Abd-Elnaser \\
5 & El-lbrahimia & 21 & El-Seiouf \\
6 & El-Talaba & 22 & Mohamed Naguib \\
7 & Cliopatra & 23 & Sedi Beshr \\
8 & Sedi Gaber & 24 & Gehan \\
9 & Mostafa Kamel & 25 & Abd El-Razek \\
10 & Roushdi & 26 & El-Academia \\
11 & Bolkly & 27 & El-Sharif \\
12 & El-Wezara & 28 & El-Asafra \\
13 & Fleming & 29 & Sedi Kamal \\
14 & Gleem & 30 & Hosni \\
15 & Zezenia & 31 & El-Mandara Gamee \\
16 & Gamee Yehia & & \\
\hline
\end{tabular}

Figure 9 shows the covered areas within $400 \mathrm{~m}$ access threshold from the bus routes in addition to the 31 bus stops locations that serve the bus routes along Gamal Abd-Elnaser roadway, numbered from west to east.

As previously discussed, if ideal access to a bus stop is identified to be a specified distance (or travel time) to a public transport stop, then it is possible to identify all of the areas within the threshold distance of all stops. Knowing these areas and their corresponding population densities, the total number of individuals in a region having suitable access to a transit stop can be determined. Simply, this is achieved using a circular GIS buffer analysis around the existing bus stops with a radius of the threshold access distance. Examining the $400 \mathrm{~m}$ ideal access coverage for the 31 existing bus stops along Gamal Abd-Elnaser roadway shows that an area of $9.86 \mathrm{Km}^{2}$ from a total routes coverage of $10.98 \mathrm{Km}^{2}$ (approximately $89.80 \%$ of the routes coverage) was found to have suitable ideal access coverage to public transit stops, as shown in Figure 10. The previous treatment may lead to an overestimation of bus stop access coverage by implying that pedestrians can reach the bus stops from any location within the circular buffer and neglecting pedestrian's real paths and the presence of possible obstacles (physical barriers), which may actually not provide full pedestrian access as the circular buffer assumes. Thus, bus stop access coverage is recalculated based on the actual pedestrian road network surrounding them. Examining the $400 \mathrm{~m}$ actual access coverage for the 31 existing bus stops along Gamal Abd-Elnaser roadway shows that only an area of $6.54 \mathrm{Km}^{2}$ from a total route coverage of $10.98 \mathrm{Km}^{2}$ (approximately $59.56 \%$ of the routes coverage) was found to have suitable actual access coverage to public transit stops, as shown in Figure 11. 


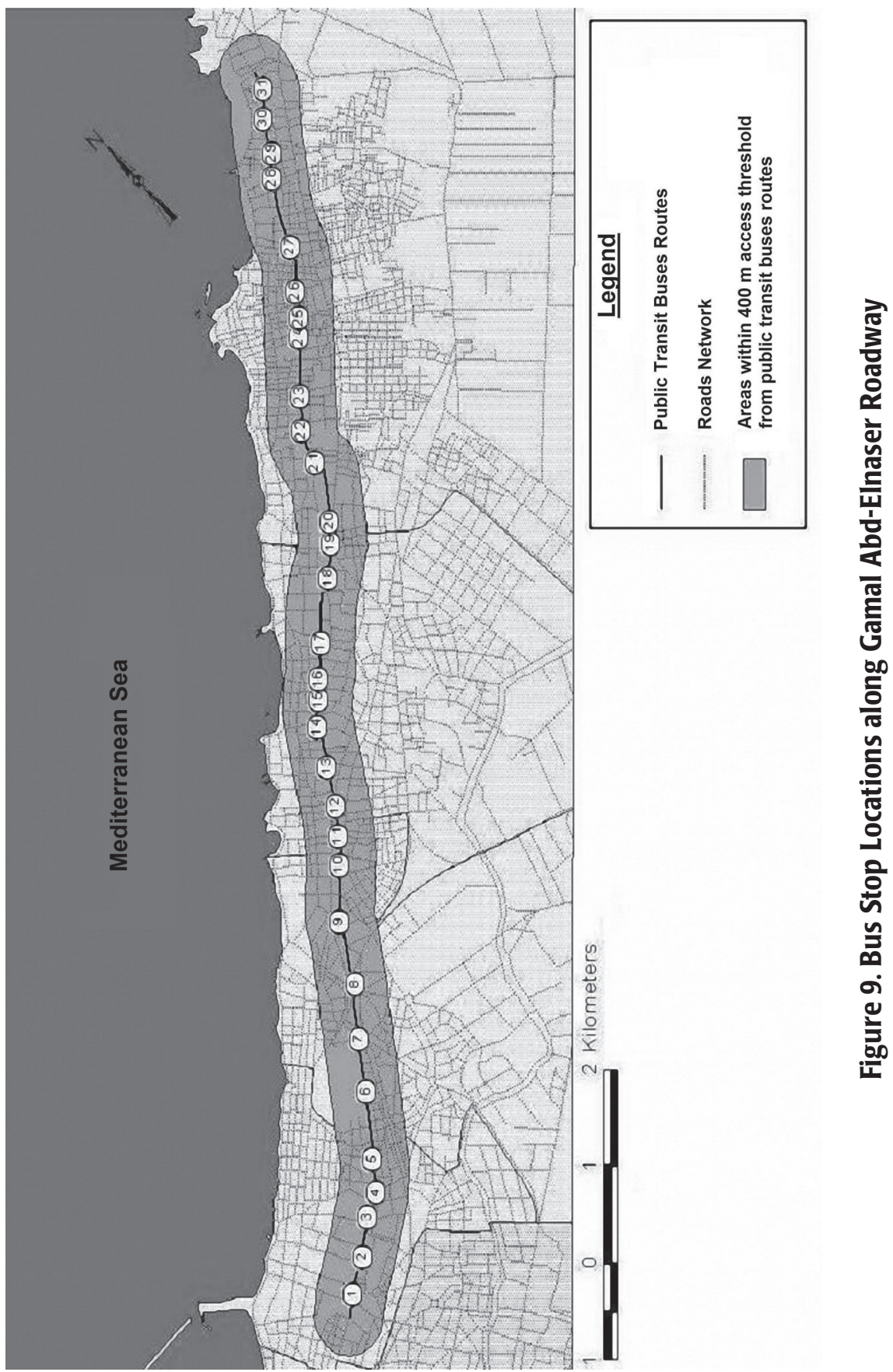




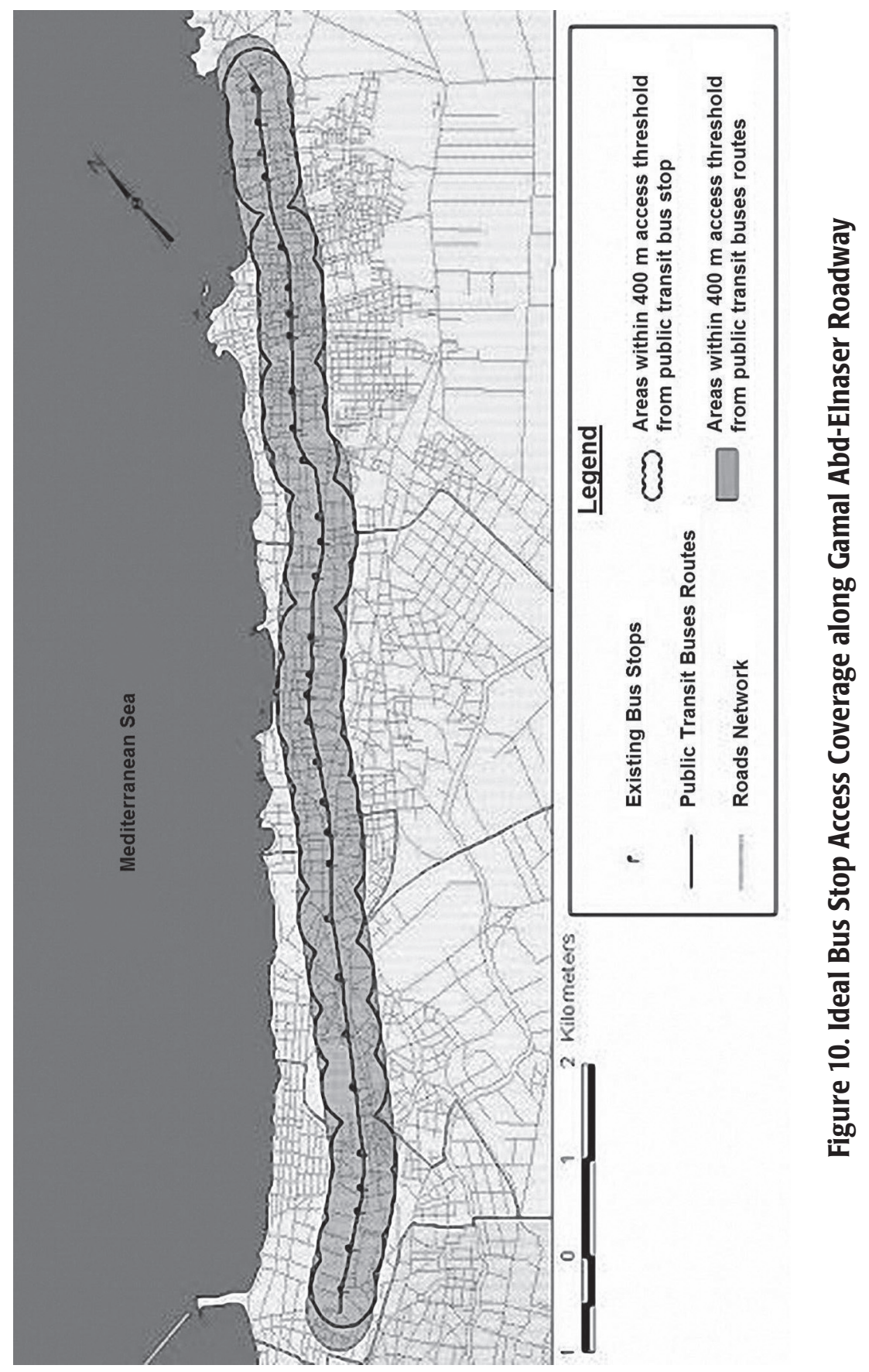




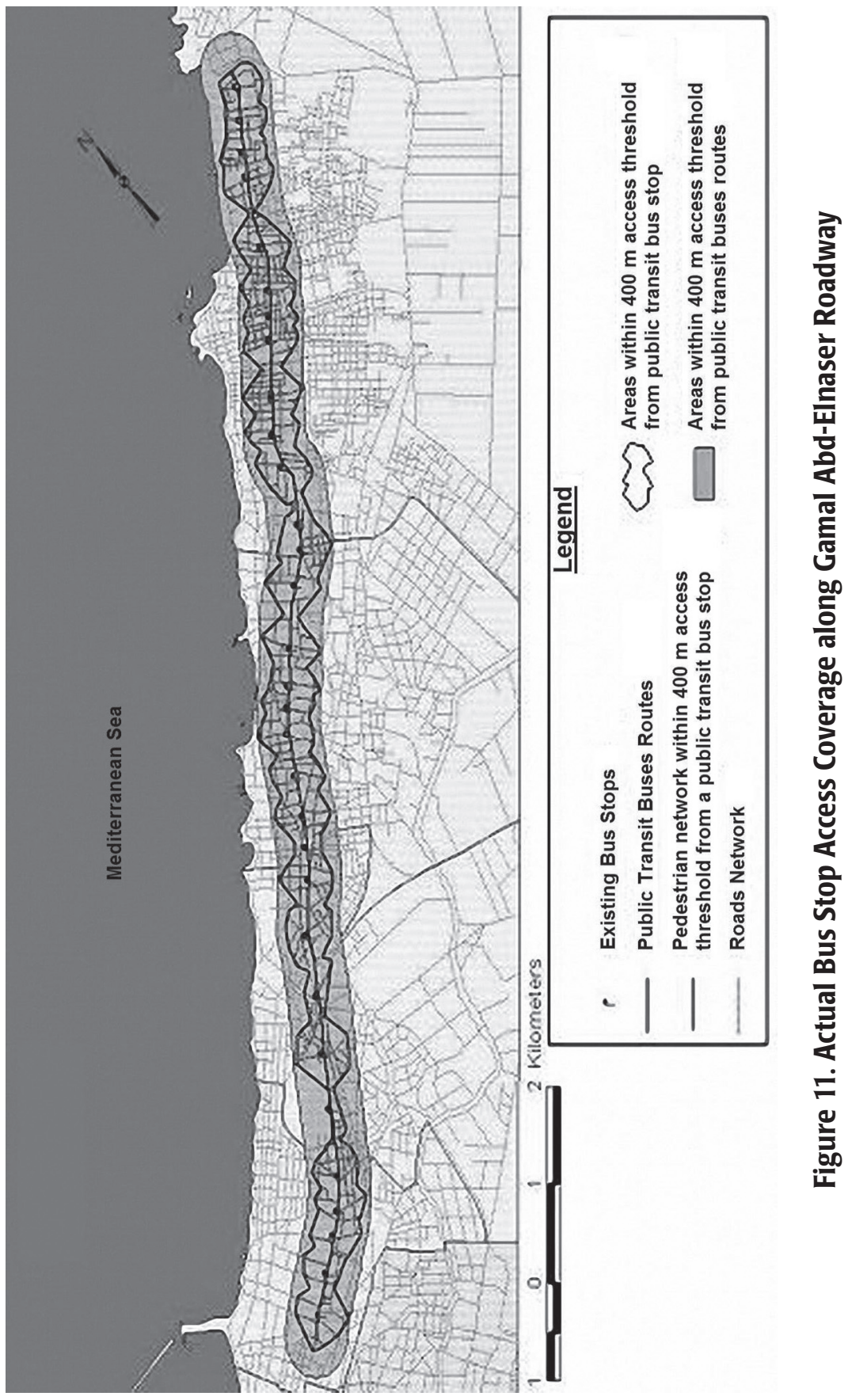


Comparing both the ideal and the actual access coverage values clearly shows that an overestimation has occurred while calculating the access coverage on bases of circular buffer around the bus stops, as it estimates the coverage area to be $9.86 \mathrm{Km}^{2}$ while it is only $6.54 \mathrm{Km}^{2}$ on basis of actual coverage and considering the pedestrian's real paths. In other words, the actual bus stop access coverage was overestimated by about $3.32 \mathrm{Km}^{2}$ (approximately $30.24 \%$ of the route coverage), which represents a difference of about 50.76 percent in estimating bus stop access coverage.

\section{Evaluating ISAI, ASAI \& SCRI for Gamal Abd-Elnaser Roadway Bus Stops}

As a step toward a more detailed analysis using the presented indices, the ISAI, ASAI, and SCRI were calculated for each stop along Gamal Abd-Elnaser roadway individually in order to evaluate both the accessibility of each bus stop through its surrounding pedestrian road network and the ratio of actual access coverage to the ideal access coverage at the stop location, as shown in Table 2.

From Table 2, it can be shown that El-Talaba (stop \#6) has the minimum ISAI value, which means that the stop has the minimum pedestrian road network length serving it within the suitable walking standard and, hence, it is not likely to be accessible. Inversely, it can be shown that El-Academia (stop \#26) has the maximum ISAI value, which means that the stop has the maximum accessibility among the rest of the stops.

On the other hand, and while evaluating the ASAI values, it was found that El-Nagda (stop \#2) has the least value of the index, which means that it has the minimum actual pedestrian road network density among the rest of the stops, and, again, the El-Academia bus stop achieved the highest value of the index, which means that it has the maximum actual pedestrian road network density among the rest of the stops, which is an indication of the suitability of its location from a spatial perspective. As previously discussed, it should be noted that the actual access coverage area and its shape are affected by the geometry and formation of the pedestrian road network surrounding the bus stop within the suitable walking limit and, thus, the ASAI may be misleading if used to compare the accessibility of different bus stops locations.

Finally, while evaluating the SCRI, it was shown that the El-Talaba bus stop has the least SCRI value, which means that it has the least actual access coverage area. Inversely, Cleopatra (stop \#7) is found to have the highest SCRI value, which means that it has the highest actual access coverage area among the stops. 
Table 2. ISAI, ASAI, and SCRI Values for Bus Stops along Gamal Abd-Elnaser Roadway

\begin{tabular}{|c|c|c|c|c|c|c|c|}
\hline $\begin{array}{l}\text { Stop } \\
\text { No. }\end{array}$ & Stop Name & $\begin{array}{c}400 \mathrm{~m} \\
\text { ideal } \\
\text { access } \\
\text { coverage } \\
\left(\mathrm{Km}^{2}\right)\end{array}$ & $\begin{array}{c}400 \mathrm{~m} \\
\text { actual } \\
\text { access } \\
\text { coverage } \\
\left(\mathrm{Km}^{2}\right)\end{array}$ & $\begin{array}{l}\text { Pedestrian } \\
\text { road network } \\
\text { within } 400 \mathrm{~m} \\
(\mathrm{Km})\end{array}$ & $\begin{array}{c}\text { ISAI } \\
\left(\mathrm{Km} / \mathrm{Km}^{2}\right)\end{array}$ & $\begin{array}{c}\text { ASAl } \\
\left(\mathrm{Km} / \mathrm{Km}^{2}\right)\end{array}$ & SCRI \\
\hline 1 & Sharki & 0.503 & 0.316 & 3.221 & 6.40 & 10.19 & 0.63 \\
\hline 2 & El-Nagda & 0.503 & 0.258 & 2.418 & 4.81 & 9.37 & 0.51 \\
\hline 3 & El-Manara & 0.503 & 0.325 & 3.407 & 6.77 & 10.48 & 0.65 \\
\hline 4 & El-Hadara & 0.503 & 0.306 & 3.971 & 7.89 & 12.98 & 0.61 \\
\hline 5 & El-Ibrahimia & 0.503 & 0.289 & 4.814 & 9.57 & 16.66 & 0.57 \\
\hline 6 & El-Talaba & 0.503 & 0.073 & 1.489 & 2.96 & 20.40 & 0.15 \\
\hline 7 & Cleopatra & 0.503 & 0.365 & 5.184 & 10.31 & 14.20 & 0.73 \\
\hline 8 & Sedi Gaber & 0.503 & 0.182 & 2.514 & 5.00 & 13.81 & 0.36 \\
\hline 9 & Mostafa Kamel & 0.503 & 0.334 & 4.570 & 9.09 & 13.68 & 0.66 \\
\hline 10 & Roushdi & 0.503 & 0.331 & 5.082 & 10.10 & 15.35 & 0.66 \\
\hline 11 & Bolkly & 0.503 & 0.217 & 2.530 & 5.03 & 11.66 & 0.43 \\
\hline 12 & El-Wezara & 0.503 & 0.346 & 5.133 & 10.20 & 14.84 & 0.69 \\
\hline 13 & Fleming & 0.503 & 0.328 & 4.601 & 9.15 & 14.03 & 0.65 \\
\hline 14 & Gleem & 0.503 & 0.352 & 4.786 & 9.51 & 13.60 & 0.70 \\
\hline 15 & Zezenia & 0.503 & 0.312 & 4.308 & 8.56 & 13.81 & 0.62 \\
\hline 16 & Gamee Yehia & 0.503 & 0.299 & 4.170 & 8.29 & 13.95 & 0.59 \\
\hline 17 & Ghanaklis & 0.503 & 0.324 & 4.176 & 8.30 & 12.89 & 0.64 \\
\hline 18 & Sharawy & 0.503 & 0.31 & 3.716 & 7.39 & 11.99 & 0.62 \\
\hline 19 & Victorya & 0.503 & 0.363 & 5.013 & 9.97 & 13.81 & 0.72 \\
\hline 20 & Gamal Abd-Elnaser & 0.503 & 0.16 & 2.168 & 4.31 & 13.55 & 0.32 \\
\hline 21 & El-Seiouf & 0.503 & 0.322 & 4.291 & 8.53 & 13.33 & 0.64 \\
\hline 22 & Mohamed Naguib & 0.503 & 0.299 & 4.348 & 8.64 & 14.54 & 0.59 \\
\hline 23 & Sedi Beshr & 0.503 & 0.33 & 6.336 & 12.60 & 19.20 & 0.66 \\
\hline 24 & Gehan & 0.503 & 0.323 & 6.519 & 12.96 & 20.18 & 0.64 \\
\hline 25 & Abd El-Razek & 0.503 & 0.318 & 6.618 & 13.16 & 20.81 & 0.63 \\
\hline 26 & El-Academia & 0.503 & 0.325 & 6.992 & 13.90 & 21.51 & 0.65 \\
\hline 27 & El-Sharif & 0.503 & 0.324 & 6.393 & 12.71 & 19.73 & 0.64 \\
\hline 28 & El-Asafra & 0.503 & 0.324 & 5.374 & 10.68 & 16.59 & 0.64 \\
\hline 29 & Sedi Kamal & 0.503 & 0.291 & 4.974 & 9.89 & 17.09 & 0.58 \\
\hline 30 & Hosni & 0.503 & 0.278 & 3.907 & 7.77 & 14.05 & 0.55 \\
\hline 31 & El-Mandara Gamee & 0.503 & 0.227 & 3.537 & 7.03 & 15.58 & 0.45 \\
\hline
\end{tabular}




\section{Conclusion and Recommendations}

Using the powerful GIS network analysis functions, three indices were developed to assist in the assessment of a bus stop location, based on the interaction between the bus stop location and the actual pedestrian road network surrounding it:

- The Ideal Stop-Accessibility Index (ISAI) evaluates the accessibility of bus stops through the surrounding pedestrian road network and can be used to assess and compare different stop locations from a spatial perspective.

- The Actual Stop-Accessibility Index (ASAI) gives a more accurate measurement of the pedestrian road network density around a bus stop.

- The Stop Coverage Ratio Index (SCRI) evaluates the percentage of actual access coverage of a bus stop with respect to its ideal access coverage.

Further, a bus stop is considered more accessible if the pedestrian road network surrounding it is more dense and has a higher ISAI value. In addition, the SCRI represents the ratio of the actual access coverage to the ideal access coverage of a bus stop. While the ASAI value estimates the actual pedestrian road network density within the access threshold from a bus stop, it may be misleading if used to compare the accessibility of different bus stop locations.

It is recommended that an extensive detailed analysis be performed for the developed indices in order to study how the geometry of the surrounding pedestrian road network could affect the values of the indices. This study could help transit planners in evaluating the locations of transit stops on a spatial basis rather than just spacing and circular access coverage, in order to select the most suitable places for locating new bus stops or for reallocating currently existing bus stops.

Potential areas for continuing the present study include the following:

1. Accessibility and linkage with potential users of the bus stop and using information on population densities for different urban districts and transforming it in terms of persons per km; hence, an extra important attribute for the polyline layer can be added other than the travel distance or time. This can be viewed as a three dimensional coordinate where the third dimension represents the population. Moreover, the effect of time on the demand variability also can be introduced through the use of appropriate data in morning/evening peak periods or even on a seasonal basis.

2. Distribution of potential users within the circular buffer zone-for example, by creating various circles radiating from the location of the bus stop with 
$50 \mathrm{~m}$ increments and locating the share of the total road network length in $\mathrm{km}$ within each.

\section{References}

Ammons, D. N. 2001. Municipal Benchmarks: Assessing Local Performance and Establishing Community Standards, Second Edition. Sage, Thousand Oaks, CA.

Central Ohio Transit Authority. 1999. Planning and development guidelines for public transit. COTA, Columbus, $\mathrm{OH}$.

Foda, M. A., and Osman, A. O. 2006. GIS tools to analyze the public bus transit service network, case study: The City of Alexandria. 16th International Conference on Computer Theory and Applications (ICCTA), Alexandria, Egypt, 5-7 September 2006.

Foda, M. A., and Osman, A. O. 2008. A GIS approach to study the bus transit network accessibility, case study: The City of Alexandria. Journal of Arab Academy for Science, Technology and Maritime Transport 34(65): 32-39.

Holtzclaw, J. 1994. Using Residential Patterns and Transit to Decrease Auto Dependence and Costs. National Resources Defence Council for California Home Energy Rating Systems, June.

Levinson, H. S. 1992. Urban mass transit systems. In Edwards, J. D. (ed.), Transportation Planning Handbook. Prentice Hall, New Jersey.

Murray, A. T., and Wu, X. 2003. Accessibility tradeoffs in public transit planning. Journal of Geographical Systems 5(1): 93-107.

Murray et al. 1998. Public transportation access. Transportation Research Part D 3(5): 319-328.

Salvo, G., and Sabatini, S. 2005. A GIS approach to evaluate bus stop accessibility. Proceedings of the 16th Mini-Euro conference and 10th meeting of EWGT, Poznan.

TCRP. 1996. Transit Cooperative Research Program Report 19, Guidelines for the Location and Design of Bus Stops. Transportation Research Board. National Academy Press. Washington, DC. 


\section{About the Authors}

Mohamed A. FodA (mfoda@aast.edu) heads the Transportation Group and related laboratories at the Arab Academy for Science \& Technology in Alexandria, Egypt. He earned Master's and Ph.D. degrees from the Civil Engineering \& Applied Mechanics Department at McGill University in Canada. His research interests include off-the road mobility, vehicle-ground interaction problems, tire slippage/traction mechanisms and the application of finite element methods, computer simulation and modeling, application of Geographic Information System to Transportation Engineering (GIS-T), and developing applicable tools using GIS for transit.

Ahmed O. Osman (a.osman@utoronto.ca) received a B.S. with honors from the Arab Academy for Science and Technology and Maritime Transport (AASTMT) in Alexandria, Egypt, and currently is a Ph.D. student in the Department of Civil Engineering at the University of Toronto in Canada. His areas of interest include public transportation, Geographic Information Systems for Transportation applications (GIS-T), Intelligent Transportation Systems (ITS), Advanced Public Transportation Systems (APTS), and transportation planning and demand analysis. 